University of Wollongong

Research Online

Australian Institute for Innovative Materials -

Papers

Australian Institute for Innovative Materials

$1-1-2016$

Boric acid assisted reduction of graphene oxide: A promising material for sodium ion batteries

Ying Wang

University of Wollongong, yw826@uow.edu.au

Caiyun Wang

University of Wollongong, caiyun@uow.edu.au

Yijing Wang

Nankai University

Hua-Kun Liu

University of Wollongong, hua@uow.edu.au

Zhenguo Huang

University of Wollongong, zhenguo@uow.edu.au

Follow this and additional works at: https://ro.uow.edu.au/aiimpapers

Part of the Engineering Commons, and the Physical Sciences and Mathematics Commons

Research Online is the open access institutional repository for the University of Wollongong. For further information contact the UOW Library: research-pubs@uow.edu.au 


\title{
Boric acid assisted reduction of graphene oxide: A promising material for sodium ion batteries
}

\author{
Abstract \\ Reduced graphene oxide, an intensively investigated material for Li-ion batteries, has shown mostly \\ unsatisfactory performance in Na-ion batteries, since its $\mathrm{d}$-spacing is believed to be too small for effective \\ insertion/deinsertion of $\mathrm{Na}+$ ions. Herein, a facile method was developed to produce boron-functionalized \\ reduced graphene oxide (BF-rGO), with an enlarged interlayer spacing and defect-rich structure, which \\ effectively accommodates the sodiation/desodiation and provides more active sites. The $\mathrm{Na} / \mathrm{BF}-\mathrm{rGO}$ half \\ cells exhibit unprecedented long cycling stability, with $\sim 89.4 \%$ capacity retained after 5000 cycles \\ $(0.002 \%$ capacity decay per cycle) at $1000 \mathrm{~mA} \cdot \mathrm{g}-1$ current density. High specific capacity ( $280 \mathrm{mAh} \cdot \mathrm{g}-1)$ \\ and great rate capability were also delivered in the $\mathrm{Na} / \mathrm{BF}-\mathrm{rGO}$ half cells. \\ Disciplines \\ Engineering | Physical Sciences and Mathematics

\section{Publication Details} \\ Wang, Y., Wang, C., Wang, Y., Liu, H. \& Huang, Z. (2016). Boric acid assisted reduction of graphene oxide: A \\ promising material for sodium ion batteries. ACS Applied Materials and Interfaces, 8 (29), 18860-18866.
}




\section{Boric Acid Assisted Reduction of Graphene Oxide:}

\section{A Promising Material for Sodium-ion Batteries}

Ying Wang, ${ }^{1,4}$ Caiyun Wang, ${ }^{3}$ Yijing Wang, ${ }^{2 *}$ Huakun Liu, ${ }^{4}$ Zhenguo Huang ${ }^{4 *}$

${ }^{1}$ School of Chemistry and Chemical Engineering, Jiangsu Key Laboratory of Green Synthetic Chemistry for Functional Materials, Jiangsu Normal University, Xuzhou, Jiangsu 221116, China.

${ }^{2}$ Collaborative Innovation Centre of Chemical Science and Engineering (Tianjin), Key Laboratory of Advanced Energy Materials Chemistry (MOE), Nankai University, Tianjin 300071, China. E-mail: wangyj@nankai.edu.cn

${ }^{3}$ Intelligent Polymer Research Institute, ARC Centre of Excellence for Electromaterials Science, University of Wollongong, Wollongong, NSW 2522, Australia.

${ }^{4}$ Institute for Superconducting and Electronic Materials, University of Wollongong, Wollongong, NSW 2522, Australia. E-mail: zhenguo@uow.edu.au.

\section{KEYWORDS:}

Sodium-ion batteries; Anode materials; Graphene oxide; Expended interlayer; Boron; Boric acid

ABSTRACT: Reduced graphene oxide, an intensively investigated material for Li-ion batteries, has shown mostly unsatisfactory performance in Na-ion batteries, since its $d$-spacing is believed 
to be too small for effective insertion/de-insertion of $\mathrm{Na}^{+}$ions. Herein, a facile method has been developed to produce boron-functionalized reduced graphene oxide (BF-rGO), with an enlarged interlayer spacing and defect-rich structure, which effectively accommodates the sodiation/desodiation and provides more active sites. The $\mathrm{Na} / \mathrm{BF}-\mathrm{rGO}$ half cells exhibit unprecedented long cycling stability, with about $89.4 \%$ capacity retained after 5000 cycles ( $0.002 \%$ capacity decay per cycle) at $1000 \mathrm{~mA} \cdot \mathrm{g}^{-1}$ current density. High specific capacity (280 $\mathrm{mAh} \cdot \mathrm{g}^{-1}$ ) and great rate capability were also delivered in the $\mathrm{Na} / \mathrm{BF}-\mathrm{rGO}$ half cells.

\section{INTRODUCTION}

Successful development of Li-ion batteries (LIBs) has promoted its application in loadleveling. ${ }^{1-5}$ The high demand for LIBs, however, has led to increasing concern about the limited resources and high cost of lithium. Consequently, great efforts have been spent on finding alternatives to LIBs. ${ }^{6-11}$ Amongst all the candidates, Na-ion batteries (NIBs) have attracted much attention due to the high deposit and low cost of sodium. The radius of $\mathrm{Na}^{+}$is about $55 \%$ larger than that of $\mathrm{Li}^{+}$, so that it requires larger channels (minimum space of $0.37 \mathrm{~nm}$ ) ${ }^{12}$ for its diffusion. ${ }^{13-14}$ This is why reduced graphene oxide (rGO, $d$-spacing: $0.34 \mathrm{~nm}$ ), which is widely used in LIBs, fails to deliver a decent performance in NIBs.

The use of carbon-based materials in NIBs, however, is still highly advantageous due to their high abundance and low cost. To date, studies on carbon materials for $\mathrm{Na}^{+}$storage are focused mainly on poorly or non-graphitized hard carbon. Various sources, such as glucose, banana peels, and polyaniline, have been used to produce hard carbon, which delivers high capacities (100 to $200 \mathrm{mAh} \cdot \mathrm{g}^{-1}$ ) and good rate capability. ${ }^{15-17}$ Hard carbon, however, often features poor cycling stability, and degraded Coulombic efficiency (CE). ${ }^{18}$ 
rGO has demonstrated excellent cycling stability and high capacity in LIBs, but has not received comparable attention in NIBs. This is likely because its $d$-spacing is smaller than 0.37 nm. In 2014, Wang et al. synthesized rGO with an expanded $d$-spacing of $0.42 \mathrm{~nm}$ by controlling the reduction temperature, and the larger interlayer spacing was reported to improve Na-ion storage capability $\left(184 \mathrm{mAh} \cdot \mathrm{g}^{-1}\right.$ at a current density of $100 \mathrm{~mA} \cdot \mathrm{g}^{-1}$ for $\left.2000 \mathrm{cycles}\right) .{ }^{18}$ Another strategy to enhance the electrochemical properties of rGO is chemical decoration by heteroatoms $(\mathrm{N}, \mathrm{P}, \mathrm{B}$, etc.). The introduced heteroatoms create more defects and change the electronic conductivity of rGO so as to promote Na-ion storage. ${ }^{19-21}$ For example, N-doped rGO foam delivered a high capacity of $594 \mathrm{mAh} \cdot \mathrm{g}^{-1}$, which outperformed pure rGO. ${ }^{22}$ Inspired by the above-mentioned methods, finding a suitable way to simultaneously expand the interlayer spacing and to chemically modify rGO with heteroatoms would be highly desirable for enhancing its Na-ion storage performance.

Boron is an ideal candidate to functionalize rGO, due to its lower electronegativity and similar atomic radius to carbon. ${ }^{23-24}$ In addition, the strong chemical bonds between boron and oxygen (B-O-) can serve as pillars to enlarge the interlayer spacing of rGO. First-principles calculations predicted the superior sodiation of boron doped $\mathrm{rGO}$, which outperformed other hard carbon and pure graphene materials. ${ }^{24}$ Experimental results on the sodiation/desodiation performance of boron functionalized rGO (BF-rGO) are rarely available. Normally, methods used to incorporate $\mathrm{B}$ into the rGO lattice require high temperatures, long time, or toxic precursors. ${ }^{25-27}$ Herein, we report a gentle method to fabricate BF-rGO, which features expanded interlayer spaces and defect-rich structure. The Na/BF-rGO half cells deliver a high reversible capacity of 280 $\mathrm{mAh} \cdot \mathrm{g}^{-1}$ and great rate capability. More importantly, ultra-long cycling stability was achieved, with high capacity retention of $89.4 \%$ after 5000 cycles (corresponding to $0.002 \%$ capacity 
decay per cycle) at a current density of $1000 \mathrm{~mA} \cdot \mathrm{g}^{-1}$. The continuous insertion/de-insertion of $\mathrm{Na}^{+}$between BF-rGO layers was also confirmed.

\section{EXPERIMENTAL METHODS}

Graphene oxide (GO) was synthesized according to our previous work. ${ }^{28}$ Typically, the BFrGO was prepared via a one-pot hydrothermal procedure: $100 \mathrm{mg}$ GO was dispersed in $70 \mathrm{ml}$ aqueous solution and then ultrasonic for $0.5 \mathrm{~h}$. Then, boric acid ( $3 \mathrm{~g})$ was added into the GO suspension and stirred for another half an hour. The well dispersed boric acid and GO mixture were kept inside an autoclave, and maintained at $180{ }^{\circ} \mathrm{C}$ for $12 \mathrm{~h}$. Finally, the samples were washed 5 times with distilled water. To obtain a porous structure, freeze-drying was employed to remove water from the BF-rGO powder. Sufficient washing was crucial for removing the extra boric acid and other potential by-products. For comparison, pure rGO was synthesized without the addition of boric acid. The final powders turned from yellow-brown to black, indicating the reduction of GO.

The details of characterization and electrochemical tests are given in the "Supporting Information". To optimize the electrochemical performance, electrolytes consisting of $1 \mathrm{M}$ $\mathrm{NaClO}_{4}$ in three different solvents were used: (1) 1,2-dimethoxyethane (DME); (2) ethylene carbonate (EC) and diethyl carbonate (DEC) (EC:DEC, 1:1, v:v ); (3) EC:DEC with the addition of $5 \%$ fluorinated ethylene carbonate (FEC) (EC:DEC:FEC).

\section{RESULTS AND DISCUSSION}

The synthesize procedure of the BF-rGO is illustrated in Figure 1. Typically, when boric acid is added to the GO suspension, strong intermolecular hydrogen bonding takes place between the hydroxyl groups in boric acid and the hydroxyl and carboxyl groups in GO. The extended hydrogen network is reflected in Figure S1 (Supporting Information), which shows red-shifted 
B-O-H out-of-plane bending (from 816 to $725 \mathrm{~cm}^{-1}$ ) and $\mathrm{O}-\mathrm{B}-\mathrm{O}$ ring bending (from 652 to $\left.632 \mathrm{~cm}^{-1}\right) .{ }^{29}$ When $\mathrm{GO}$ was reduced to $\mathrm{rGO}$, the $\mathrm{B}-$ containing functional groups $(-\mathrm{B}-\mathrm{O}-\mathrm{C}-/-\mathrm{B}-\mathrm{C}-\mathrm{O}-)$ survived in the resultant $\mathrm{BF}-\mathrm{rGO}$ (shown in Figure $\mathrm{S} 2$ ).

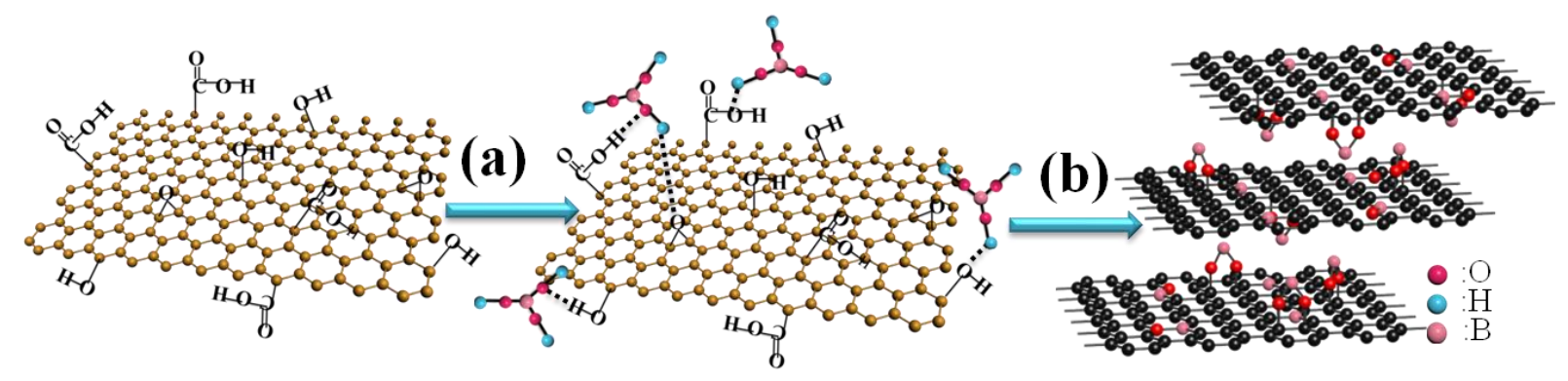

Figure 1. Synthesis of BF-rGO: (a) Dispersion of boric acid in rGO suspension, (b) formation of the BF-rGO via a hydrothermal process.

The structure of the resultant samples was further characterized (Figure 2). Compared with $\mathrm{GO}$, the (002) reflection for the rGO and BF-rGO in the X-ray powder diffraction patterns (XRD, Figure 2a) shifts to a higher angle, indicating the removal of large amounts of functional groups during the hydrothermal process. The (002) reflection of $\mathrm{rGO}$ at $26.7^{\circ}$ is associated with an interlayer spacing of $\sim 0.34 \mathrm{~nm}$. The (002) reflection of the $\mathrm{BF}-\mathrm{rGO}$ is located at $24.3^{\circ}$, indicating a larger interlayer space of $\sim 0.37 \mathrm{~nm}$, which has been predicted large enough to facilitate $\mathrm{Na}^{+}$ion insertion/de-insertion.

Raman spectroscopy further reveals the differences between rGO and BF-rGO (Figure 2b). The prominent peak at $1320-1338 \mathrm{~cm}^{-1}$ is assigned to the $\mathrm{D}$ bond, and the prominent peak at $1580-1590 \mathrm{~cm}^{-1}$ is assigned to the $\mathrm{G}$ bands in carbon. The $\mathrm{D}$ band is associated with disorder, and the $\mathrm{G}$ band relates to the stretching of $s p^{2}$ atoms. GO and $\mathrm{rGO}$ both display their $\mathrm{D}$ and $\mathrm{G}$ bands around 1335 and $1548 \mathrm{~cm}^{-1}$, respectively. For BF-rGO, obvious peak shifts are observed. The blue shift in the $\mathrm{G}$ band $\left(1589 \mathrm{~cm}^{-1}\right)$ is due to the different bond distances between $\mathrm{C}-\mathrm{C}$ and 
$\mathrm{C}-\mathrm{B}$, indicating the incorporation of $\mathrm{B}$ into the two-dimensional (2D) structure of rGO. ${ }^{19,22}$ Compared with rGO, the red shift in the D band indicates different ordering of the BF-rGO. The intensity ratio of the $\mathrm{D}$ to the $\mathrm{G}$ band $\left(I_{\mathrm{D}} / I_{\mathrm{G}}\right)$ in the $\mathrm{GO}, \mathrm{rGO}$, and $\mathrm{BF}-\mathrm{rGO}$ is $1.03,1.07$, and 1.27 , respectively. In general, $I_{\mathrm{D}} / I_{\mathrm{G}}$ varies inversely with crystallization. The highest value of $I_{\mathrm{D}} / I_{\mathrm{G}}$ in the BF-rGO indicates a defect-rich structure. This defect-rich structure facilitates sufficient contact between the electrode and electrolyte, and is favorable for ion diffusion. ${ }^{30-31}$

X-ray photoelectron spectroscopy (XPS, Figure 2c) confirmed the high purity of resultant samples, as only C, O, and B were observed. The oxygen content (Figure 2d) in BF-rGO is higher than that of rGO, but lower than for GO. The oxygen-containing groups are necessary for enlarging the interlayer spacing, but excess groups decrease the electronic conductivity. ${ }^{17}$ Since the $\mathrm{B}-\mathrm{O}$ bond $\left(125 \mathrm{~kJ} \mathrm{~mol}^{-1}\right)$ is stronger than the $\mathrm{C}-\mathrm{O}$ bond $\left(85.5 \mathrm{~kJ} \mathrm{~mol}^{-1}\right)$, it could survive this reduction reaction and therefore help to enlarge the interlayer spacing. The atomic content of boron is 2.4 at.\% in the $\mathrm{BF}-\mathrm{rGO}$. The $\mathrm{C}$ 1s high resolution spectrum of the BF-rGO reveals that most of the carbon exists in the $s p^{2}$ state, located at $284.65 \mathrm{eV}$ (Figure 2e). Two peaks associated with the $\mathrm{B}-\mathrm{C}$ and $\mathrm{B}-\mathrm{O}-\mathrm{C}$ bonds at 283.31 and $289.10 \mathrm{eV},{ }^{19}$ respectively, are also observed. The B 1s peak (Figure 2f) can be divided into three peaks at 190.15, 191.28, and $192.28 \mathrm{eV}$, corresponding to the $\mathrm{BC}_{3}, \mathrm{BC}_{2} \mathrm{O}$, and $\mathrm{BCO}_{2}$ entities, respectively. ${ }^{26}$ Taking all the above findings into consideration, the schematic structure of the BF-rGO is given in Figure $2 \mathrm{~g}$ and $\mathrm{h}$. Boron is likely to be present in three forms: (1) substituting into the six-ring $\mathrm{C}$ to form $\mathrm{BC}_{3}$ (structure $\mathrm{A}$ ); (2) co-doping with $\mathrm{O}$ to form $\mathrm{BC}_{2} \mathrm{O}$, introducing nanovoids into the layer (structure $\mathrm{B}$ ); and (3) forming functional groups such as $\mathrm{BCO}_{2}$ (structure $\mathrm{C}$ ). The presence of these groups not only helps to expand the interlayer spacing, but also introduces defects, both of which are believed to be beneficial for sodiation/desodiation. 
The Brunauer-Emmett-Teller (BET) surface areas of rGO and BF-rGO were analyzed by $\mathrm{N}_{2}$ adsorption-desorption isotherms (Figure S3). Typical type-IV hysteresis loops are observed in both samples, indicating their mesoporous nature. The specific surface area is calculated to be 634 and $281 \mathrm{~m}^{2} \cdot \mathrm{g}^{-1}$ for $\mathrm{rGO}$ and $\mathrm{BF}-\mathrm{rGO}$, respectively. The decreased specific surface area of BF-rGO is likely caused by the incorporation of B and the preservation of oxygen-containing groups in its structure.
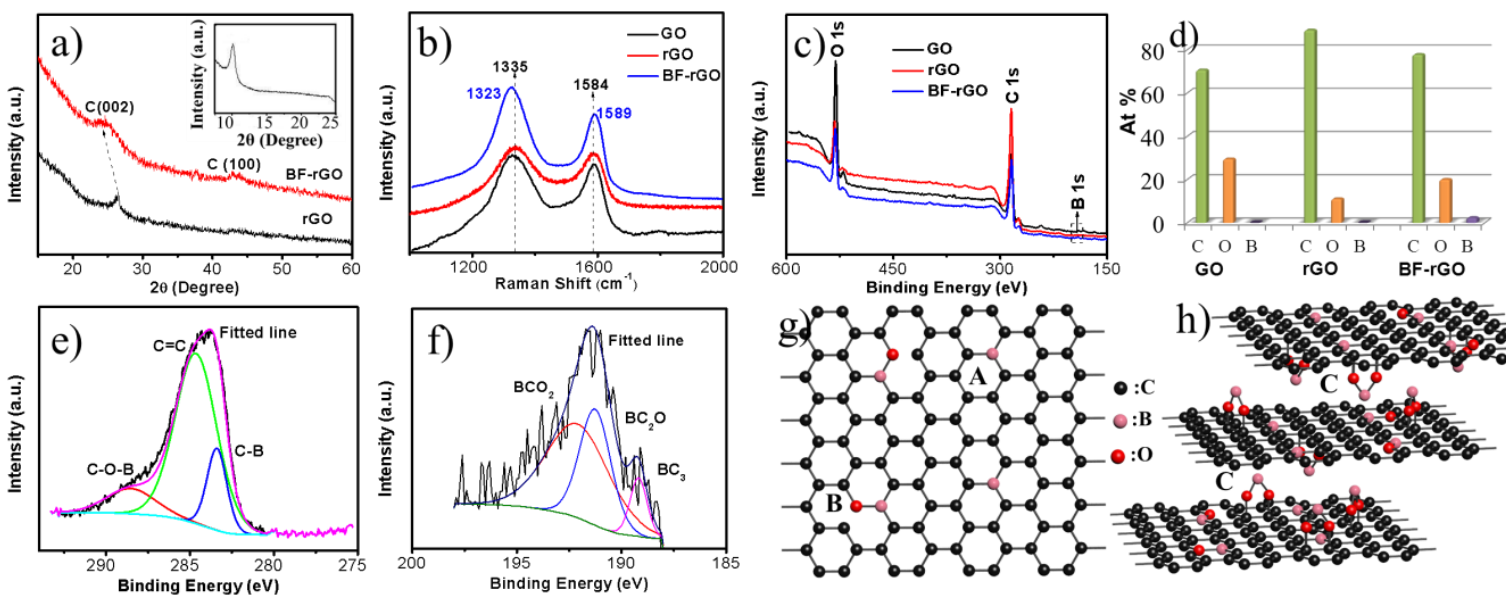

h)

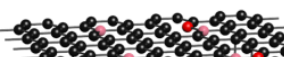

$\bullet: \mathrm{C}$

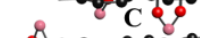

O
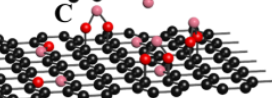

Figure 2 (a) XRD plots, (b) Raman spectra, (c) XPS analysis, and (d) atomic contents of C, O, and $\mathrm{B}$ in the $\mathrm{GO}, \mathrm{rGO}$, and $\mathrm{BF}-\mathrm{rGO}$. Inset in (a) is the XRD pattern of GO. High-resolution XPS spectra of (e) C 1s and (f) B 1s in the BF-rGO. Schematic illustrations of the BF-rGO: (g) top and $(\mathrm{h})$ side views.

The electrochemical performance of the BF-rGO was investigated. To optimize the electrochemical performance, three types of electrolytes were used (Figure 3). Compared with the first cycle profiles (shown in Figure S4), all the batteries show capacity decline in the second cycle (Figure 3a-c). The initial capacity loss can be attributed to the reactions between the electrolyte and the BF-rGO, and the irreversible insertion of $\mathrm{Na}^{+}$ions into the BF-rGO structure. 12, 16 This is commonly observed in carbon-based anode for Na-ion batteries, where the first cycle 
experiences high irreversible capacity (Table 1). In addition to the high-energy defects, the oxygen-containing functional groups in BF-rGO may also lead to irreversible $\mathrm{Na}^{+}$ion storage. ${ }^{32-}$ ${ }^{33}$ Although the Na/BF-rGO half cells in EC:DEC show higher initial discharge capacity (640 $\mathrm{mAh} \cdot \mathrm{g}^{-1}$ ) than in DME $\left(601 \mathrm{mAh} \cdot \mathrm{g}^{-1}\right.$ ), their CE is only $28.3 \%$ (about $5.2 \%$ lower than that in DME). Inspired by the LIBs where FEC was added into the electrolyte to improve the cycling stability and capacity, ${ }^{34-37}$ the electrochemical performance of Na/BF-rGO half cells with EC: DEC: FEC was also investigated. A comparison of the Na/BF-rGO half cells in those electrolytes is given in Table S1. Compared with the half cells with EC: DEC electrolyte, the half cells with FEC showed a higher capacity and better capacity retention over 115 cycles (Table S1). A higher CE of $99.6 \%$ for the half cell in EC: DEC: FEC was maintained from the $10^{\text {th }}$ cycle onwards, compared to $98.3 \%$ for the half cells in EC: DEC. At the $115^{\text {th }}$ cycle, the cells with EC: DEC: FEC delivered a stable discharge capacity of $180 \mathrm{mAh} \cdot \mathrm{g}^{-1}$, compared to $128 \mathrm{mAh} \cdot \mathrm{g}^{-1}$ for cells with EC: DEC. These results indicate that FEC may play a role in maintaining the Na-ion storage performance in Na/BF-rGO that is similar to that reported in LIBs. The stabilizing effect of FEC has also been observed in other reports. ${ }^{37}$. For comparison, the electrochemical performance of pure rGO in these electrolytes was also studied, and a similar trend was observed (Figure S5). Therefore, the electrochemical performance was investigated using $1 \mathrm{M} \mathrm{NaClO}_{4}$ in EC:DEC:FEC as electrolyte.

To evaluate the rate capability of the BF-rGO electrode, we discharged and charged the NIBs at different current densities, from 20 to $1000 \mathrm{~mA} \cdot \mathrm{g}^{-1}$ (Figure 4a). The discharge-charge profiles for the BF-rGO electrode at various current densities are given in Figure S6, which show good capacity retention when the current density increases. The electrochemical performance of pure rGO was also investigated for comparison (Figure S7). Clearly, the BF-rGO showed a high 
capacity of $280 \mathrm{mAh} \cdot \mathrm{g}^{-1}$ at $20 \mathrm{~mA} \cdot \mathrm{g}^{-1}$, about 1.6 times higher than that of pure rGO. When increasing the current density to 80,200 , and $400 \mathrm{~mA} \cdot \mathrm{g}^{-1}$, the BF-rGO electrode can still deliver 212, 176, and $153 \mathrm{mAh} \cdot \mathrm{g}^{-1}$, respectively. More importantly, even at $1000 \mathrm{~mA} \cdot \mathrm{g}^{-1}$ current density, the BF-rGO still showed a high capacity of $123 \mathrm{mAh} \cdot \mathrm{g}^{-1}$. When the current was returned to $20 \mathrm{~mA} \cdot \mathrm{g}^{-1}$, the capacity of the BF-rGO recovered to $253 \mathrm{mAh} \cdot \mathrm{g}^{-1}$, which indicates high cell integrity during the $\mathrm{Na}^{+}$insertion/de-insertion.
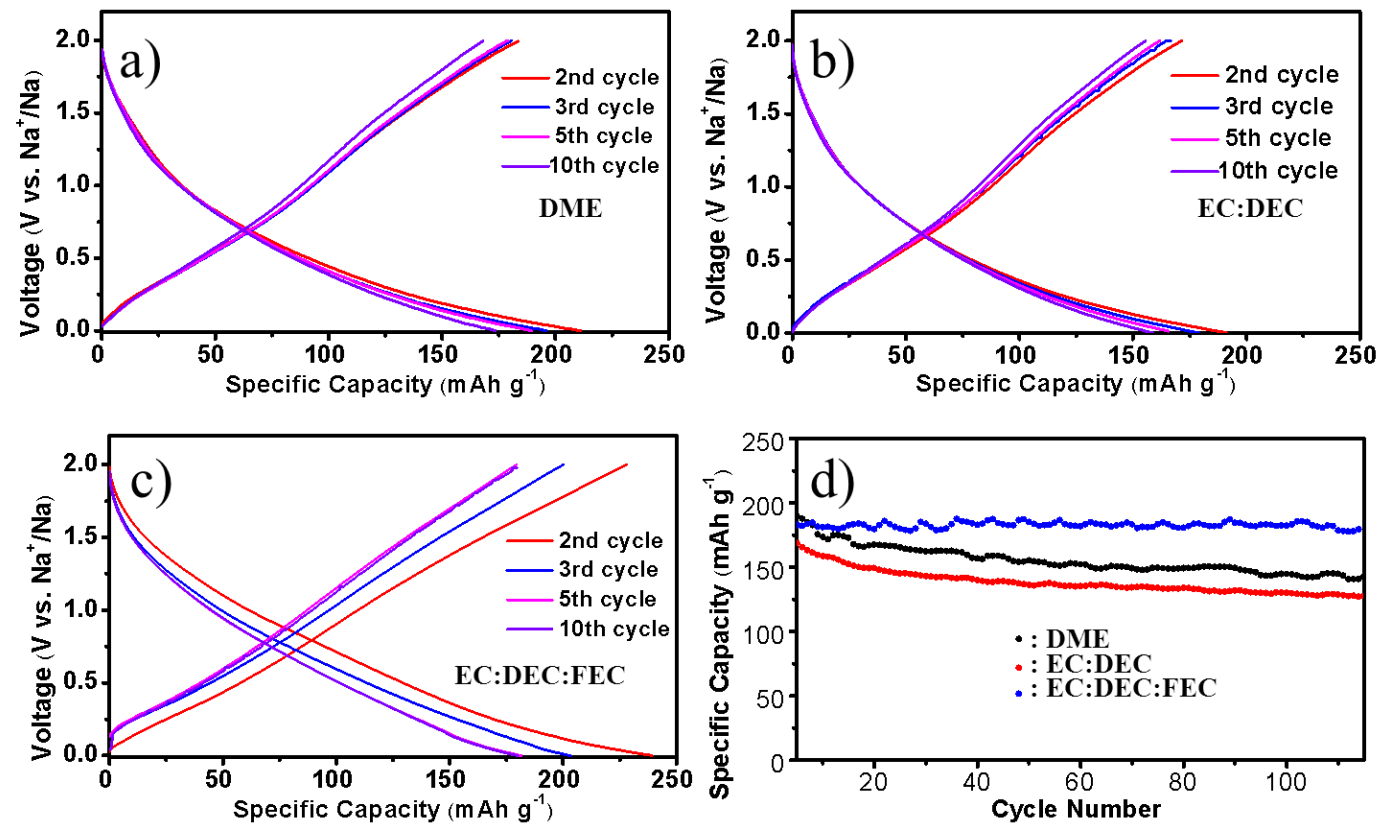

Figure 3 Electrolyte optimization for the Na/BF-rGO half-cells. (a, b, c) Discharge-charge profiles at $100 \mathrm{~mA} \cdot \mathrm{g}^{-1}$ with electrolyte consisting of $1 \mathrm{M} \mathrm{NaClO}_{4}$ in DME, EC: DEC, and EC: DEC: FEC, respectively. (d) Cycling stability in different electrolytes.

The kinetic properties were investigated by electrochemical impedance spectroscopy (Figure 4b). The depressed semicircle and the sloping line in the Nyquist plots are related to the resistance and Warburg impedance, respectively. To study the solution resistance related to electrolyte $\left(R_{\mathrm{s}}\right)$, charge-transfer resistance $\left(R_{\mathrm{ct}}\right)$, constant phase element $(\mathrm{CPE})$, and Warburg impedance ( $W$, corresponding to $\mathrm{Na}^{+}$diffusion), an equivalent electric circuit was constructed 
(inset Figure 4b). Parameters used to fit the Nyquist plots are given in Table S2. For the BF-rGO, $R_{\text {ct }}$ is calculated to be $586 \Omega$, in sharp contrast to that of the pure rGO electrode $(1509 \Omega)$. The decreased $R_{\mathrm{ct}}$ offers a lower energy barrier for sodium insertion/de-insertion, and therefore contributes to the good rate capability of the BF-rGO electrode.
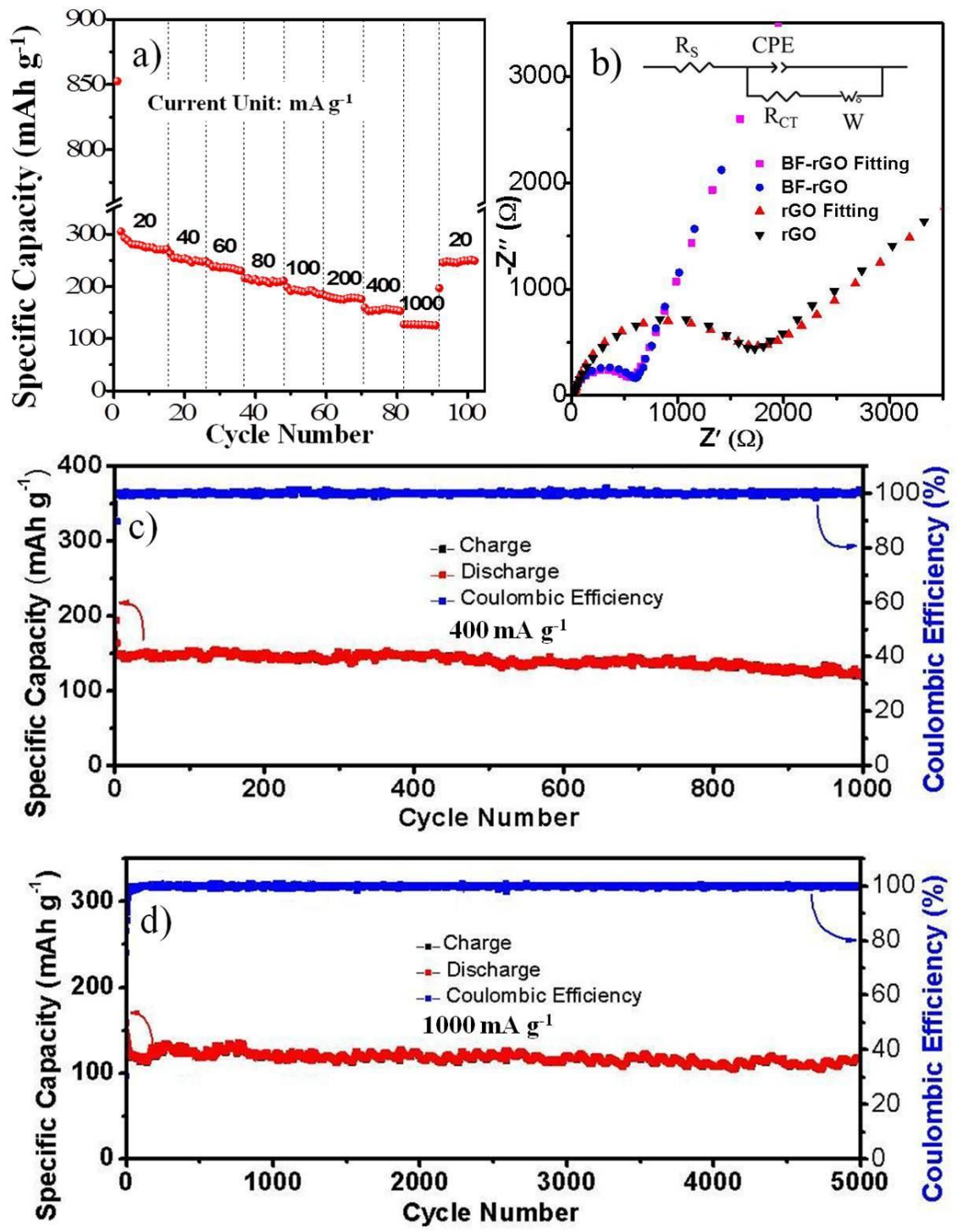

Figure 4 Electrochemical performance of BF-rGO. (a) Rate performance; (b) Nyquist plots and the fitting results. (c, d) Long-life cycling stability at 400 and $1000 \mathrm{~mA} \cdot \mathrm{g}^{-1}$. The results of rGO are shown for comparison, and inset (b) shows the equivalent electrical circuit. 
Table 1 Performance comparison of carbon-based anode materials for NIBs.

\begin{tabular}{|c|c|c|c|c|c|}
\hline Sample & $\begin{array}{l}\text { Current } \\
\left(\mathrm{mA} \cdot \mathrm{g}^{-1}\right)\end{array}$ & $\begin{array}{l}\text { Capacity } \\
\left(\mathrm{mAh} \cdot \mathrm{g}^{-1}\right)\end{array}$ & $\begin{array}{l}\text { Capacity } \\
\text { Retention }\end{array}$ & $\begin{array}{l}1^{\text {st }} \text { cycle } \\
\text { Capacity } \\
\text { Loss }(\%)\end{array}$ & Year/Ref. \\
\hline${ }^{\mathrm{a}} \mathrm{HCNW}$ & 50 & 251 & $82.5 \%$ after 400 cycles & $49 \%$ & $2012 / /^{12}$ \\
\hline${ }^{\mathrm{b}} \mathrm{HCNS}$ & 100 & 160 & $66.6 \%$ after 100 cycles & $58 \%$ & $2012 \beta^{38}$ \\
\hline rGO & 40 & 141 & $45.0 \%$ after 1000 cycles & $77 \%$ & $2013 /^{39}$ \\
\hline${ }^{\mathrm{c}} \mathrm{N}-\mathrm{CS}$ & 50 & 155 & $44.4 \%$ after 50 cycles & $65 \%$ & $2013 /^{32}$ \\
\hline${ }^{\mathrm{d}} \mathrm{FN}-\mathrm{CNF}$ & 200 & 134 & $88.7 \%$ after 200 cycles & $58 \%$ & $2013 /^{40}$ \\
\hline${ }^{\mathrm{e}} \mathrm{EG}$ & 100 & 184 & $73.9 \%$ after 2000 cycles & $50 \%$ & $2014 /^{18}$ \\
\hline${ }^{\mathrm{f}} \mathrm{G}-\mathrm{HC}$ & 20 & 274 & $94.8 \%$ after 195 cycles & $17 \%$ & $2015 /^{41}$ \\
\hline${ }^{\mathrm{g}} \mathrm{NSHC}$ & 20 & 289 & $89.1 \%$ after 100 cycles & $28 \%$ & $2015 /^{42}$ \\
\hline${ }^{\mathrm{h}} \mathrm{PCNF}$ & 50 & 196 & $81.4 \%$ after 100 cycles & $30 \%$ & $2015^{43}$ \\
\hline${ }^{\mathrm{i}} \mathrm{GF}$ & 200 & 16 & $55.5 \%$ after 200 cycles & $68 \%$ & $2015 /^{44}$ \\
\hline rGO/Juglone & 100 & 212 & $69.5 \%$ after 300 cycles & $56 \%$ & $2015^{45}$ \\
\hline${ }^{\mathrm{j}} \mathrm{CNTs}$ & 100 & 75 & $80 \%$ after 300 cycles & $20 \%$ & $2015 /^{46}$ \\
\hline${ }^{\mathrm{k}} \mathrm{F}-\mathrm{CP}$ & 200 & 228 & $99.4 \%$ after 200 cycles & $47 \%$ & $2015 /^{44}$ \\
\hline${ }^{1} \mathrm{CM}$ & 40 & 270 & $90.1 \%$ after 200 cycles & $26 \%$ & $2016 /^{47}$ \\
\hline Porous-C & 20 & 253 & $96.5 \%$ after 100 cycles & $45 \%$ & $2016 /^{48}$ \\
\hline${ }^{\mathrm{m}} \mathrm{N}-\mathrm{HCS}$ & 200 & 136 & $90.0 \%$ after 2500 cycles & $77 \%$ & $2016 /^{49}$ \\
\hline${ }^{\mathrm{n}} \mathrm{NOC}$ & 2000 & 240 & $\sim 87.0 \%$ after 2000 cycles & $\sim 18 \%$ & $2016 /^{50}$ \\
\hline BF-GO & 1000 & 117 & $89.4 \%$ after 5000 cycles & $63 \%$ & This work \\
\hline
\end{tabular}

${ }^{\mathrm{a}} \mathrm{HCNW}$ : hollow carbon nanowires, ${ }^{\mathrm{b}} \mathrm{HCNSs}$ : hollow carbon nanospheres, ${ }^{\mathrm{c}} \mathrm{N}-\mathrm{CSs}$ : nitrogendoped carbon sheets, ${ }^{\mathrm{d}} \mathrm{FN}-\mathrm{CNF}$ : functionalized nitrogen-doped carbon nanofibers, ${ }^{\mathrm{e}} \mathrm{EG}$ : 
expanded graphite, ${ }^{\mathrm{f}} \mathrm{G}-\mathrm{HC}$ : sucrose/GO derived hard carbon; ${ }^{\mathrm{g}} \mathrm{NSHC}$ : nanoporous sucrose-based hard carbon, ${ }^{\mathrm{h}} \mathrm{PCNFs}$ : porous carbon nanofiber, ${ }^{\mathrm{i}} \mathrm{GF}$ : graphite flakes, ${ }^{\mathrm{j}} \mathrm{CNTs}$ : carbon nanotubes, ${ }^{\mathrm{k}} \mathrm{F}-\mathrm{CP}$ : fluorine-doped carbon particles, ${ }^{\mathrm{l}} \mathrm{CM}$ : carbon membrane, ${ }^{\mathrm{m}} \mathrm{N}-\mathrm{HCS}$ : nitrogen doped hollow carbon nanosphere, ${ }^{\mathrm{n}} \mathrm{NOC}$ : nitrogen and oxygen dual doped carbon.

Long-life stability of the $\mathrm{Na} / \mathrm{BF}-\mathrm{rGO}$ half cells was first investigated at $400 \mathrm{~mA} \cdot \mathrm{g}^{-1}$ (Figure 4c). The BF-rGO anode shows little capacity fading during the following 1100 cycles $(\sim 130$ $\mathrm{mAh} \cdot \mathrm{g}^{-1}$ ), and a high CE of nearly $100 \%$. More importantly, at a higher specific current of 1000 $\mathrm{mA} \cdot \mathrm{g}^{-1}$, a capacity of $117 \mathrm{mAh} \cdot \mathrm{g}^{-1}$ was delivered at the end of 5000 cycles, corresponding to $89.4 \%$ capacity retention ( $0.002 \%$ capacity decay per cycle, Figure $4 d)$. The discharge-charge plot of the BF-rGO electrode after 5000 cycles is shown in Figure S8, which is similar to those of the first few cycles (Figure 3c). Such excellent cycling stability is rarely reported for carbonbased anode in NIBs under equal or even low specific currents (Table 1). The reversible capacity of $280 \mathrm{mAh} \cdot \mathrm{g}^{-1}$ at $20 \mathrm{~mA} \cdot \mathrm{g}^{-1}$ is much higher than for other reported carbon-based anode materials in NIBs. ${ }^{38,51-54}$ These significant improvements highlight the potential of the BF-rGO as anode material for NIBs.

Morphology, interlayer spacing, and structural defects all play important roles in the electrochemical performance. Both the rGO and the $\mathrm{BF}-\mathrm{rGO}$ show a layered structure with some overlapping wrinkles (Figure S9). The wrinkles create some interconnected pores, which minimizes diffusive resistance and enhances the surface area for active site dispersion. ${ }^{39}$ The TEM and HR-TEM images reveal the structural changes during cycling (Figure 5). Clear lattice fringes can be observed in $\mathrm{rGO}$, with an average interlayer spacing of $0.34 \mathrm{~nm}$. The as-obtained BF-rGO shows a slightly disordered structure with an enlarged interlayer distance $(\sim 0.37 \mathrm{~nm})$, which was caused by formation of pillars during the reaction between boric acid and the functional groups in GO. The after-cycled BF-rGO maintained the layered structure, with some winkles on the surface. Importantly, the interlayer distance of the after-cycled BF-rGO was 
further expanded into $0.42 \mathrm{~nm}$, which is likely caused by the continuous insertion/de-insertion of $\mathrm{Na}^{+}$ions between the layers.
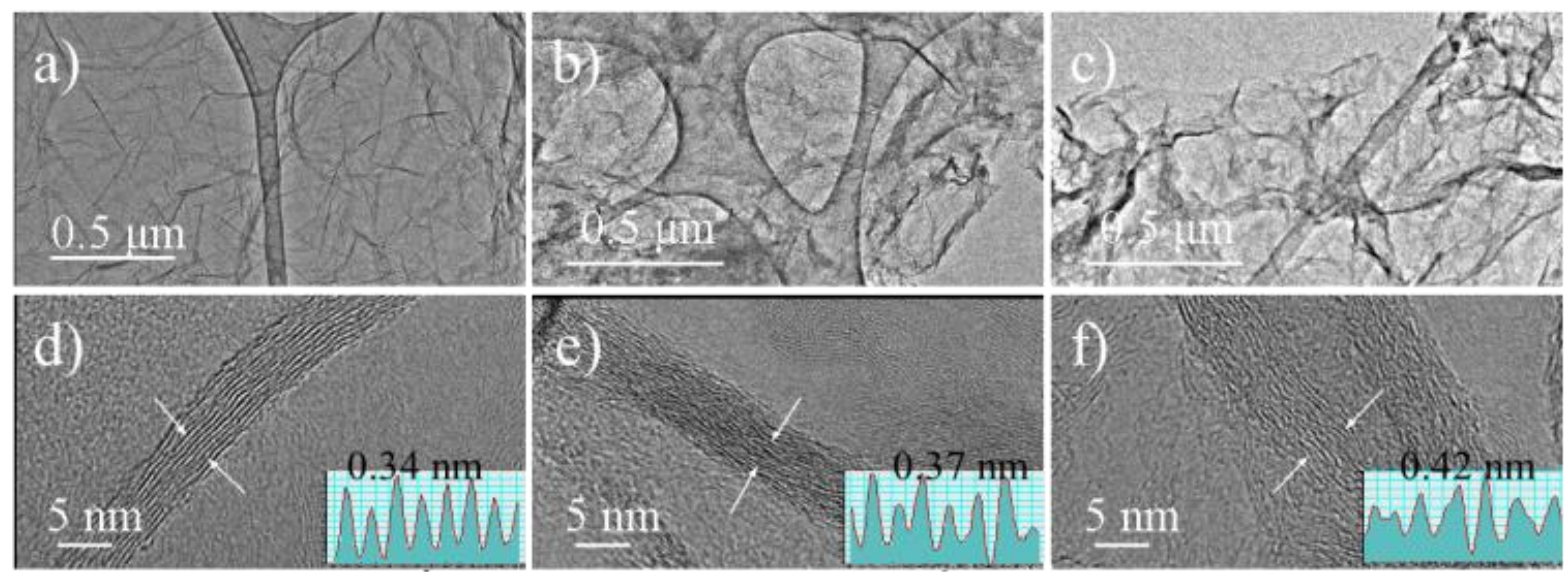

Figure 5 TEM and HR-TEM images of (a, d) rGO, (b, e) as-obtained BF-rGO, and (c, f) long-term cycled BF-rGO. Insets (d, e, f) are the contrast profiles. All the samples are in fully charged state.

The excellent performance of the BF-rGO can be attributed to the following reasons. First, enlarged interlayer distance is beneficial for $\mathrm{Na}^{+}$insertion/de-insertion. The strong $\mathrm{B}-\mathrm{O}$ bond in comparison to $\mathrm{C}-\mathrm{O}$ contributes to the formation of sturdy pillars that prevent the coalescence of graphitic layers, and the resultant expanded spacing is crucial for $\mathrm{Na}^{+}$storage. Second, the incorporation of $\mathrm{B}$ and $\mathrm{O}$ into the $\mathrm{rGO}$ basal planes introduces more active sites (e.g., voids in structure $\mathrm{B}$ in Figure $2 \mathrm{~g}$ ) that help to trap more $\mathrm{Na}^{+}$ions, leading to a higher capacity compared to rGO. In addition, the resultant $2 \mathrm{D}$ structure effectively shorten the $\mathrm{Na}^{+}$diffusion distance, and enable better contact between electrode and electrolyte.

\section{CONCLUSIONS}

In summary, BF-rGO was obtained through a one-pot hydrothermal reaction and displayed great potential as anode for NIBs. The resultant $\mathrm{BF}-\mathrm{rGO}$ features a large amount of active 
defects, and an enlarged interlayer spacing. The $\mathrm{Na} / \mathrm{BF}-\mathrm{rGO}$ half cells demonstrated excellent electrochemical performance with high reversible capacity and superior cycling stability. The strategy used in this work to simultaneously expand the interlayer spacing and introduce heteroatoms into rGO is low-cost and easy to accomplish, which makes it feasible for scaling up. This work sheds light on how to prepare rGO with expanded interlayer space by using heteroatoms such as $\mathrm{N}$ and $\mathrm{P}$, and the resultant $\mathrm{rGO}$ can be explored as high-performance NIB anode materials.

\section{ASSOCIATED CONTENT}

Supporting Information. Characterization, cells assembling, FTIR spectra, nitrogen sorption isotherms, electrochemical performance curves, SEM images, and parameters of the fitted Nyquist plots are available free of charge via the Internet at: http://pubs.acs.org.

\section{ACKNOWLEDGMENTS}

This work was supported by NSFC (51471089), MOE (IRT13R30), 111 Project (B12015), and the Priority Academic Program Development of Jiangsu Higher Education Institutions. The authors would like to thank the Australian National Nanofabrication Facility-Materials node (ANFF) for equipment use.

\section{REFERENCES}

(1) Tarascon, J. M.; Armand, M., Issues and Challenges Facing Rechargeable Lithium Batteries. Nature 2001, 414, 359-367. 
(2) Yu, S.-H.; Quan, B.; Jin, A.; Lee, K.-S.; Kang, S. H.; Kang, K.; Piao, Y.; Sung, Y.-E., Hollow Nanostructured Metal Silicates with Tunable Properties for Lithium Ion Battery Anodes. ACS Appl. Mater. Interfaces 2015, 7, 25725-25732.

(3) Tian, L.-L.; Zhang, M.-J.; Wu, C.; Wei, Y.; Zheng, J.-X.; Lin, L.-P.; Lu, J.; Amine, K.; Zhuang, Q.-C.; Pan, F., $\gamma$ - $\mathrm{Fe}_{2} \mathrm{O}_{3}$ Nanocrystalline Microspheres with Hybrid Behavior of BatterySupercapacitor for Superior Lithium Storage. ACS Appl. Mater. Interfaces 2015, 7, 2628426290.

(4) Huang, H.; Feng, T.; Gan, Y.; Fang, M.; Xia, Y.; Liang, C.; Tao, X.; Zhang, W., TiC/NiO Core/Shell Nanoarchitecture with Battery-capacitive Synchronous Lithium Storage for HighPerformance Lithium-ion Battery. ACS Appl. Mater. Interfaces 2015, 7, 11842-11848.

(5) Wang, Y.; Huang, Z.; Wang, Y., A New Approach to Synthesize $\mathrm{MoO}_{2} @ \mathrm{C}$ for High-rate Lithium Ion Batteries. J. Mater. Chem. A 2015, 3, 21314-21320.

(6) Arico, A. S.; Bruce, P.; Scrosati, B.; Tarascon, J. M.; Van Schalkwijk, W., Nanostructured Materials for Advanced Energy Conversion and Storage Devices. Nat. Mater. 2005, 4, 366-377.

(7) Wang, Z.-L.; Xu, D.; Xu, J.-J.; Zhang, X.-B., Oxygen Electrocatalysts in Metal-air Batteries: from Aqueous to Nonaqueous Electrolytes. Chem. Soc. Rev. 2014, 43, 7746-7786.

(8) Min, J.; Liu, J.; Lei, M.; Wang, W.; Lu, Y.; Yang, L.; Yang, Q.; Liu, G.; Su, N., Selfassembly of Parallelly Aligned NiO Hierarchical Nanostructures with Ultrathin Nanosheet Subunits for Electrochemical Supercapacitor Applications. ACS Appl. Mater. Interfaces 2016, 8, 780-791.

(9) Kim, H. M.; Hwang, J.-Y.; Manthiram, A.; Sun, Y.-K., High-performance Lithium-sulfur Batteries with a Self-assembled Multiwall Carbon Nanotube Interlayer and a Robust Electrodeelectrolyte Interface. ACS Appl. Mater. Interfaces 2016, 8, 983-987. 
(10) Butt, F. K.; Tahir, M.; Cao, C.; Idrees, F.; Ahmed, R.; Khan, W. S.; Ali, Z.; Mahmood, N.; Tanveer, M.; Mahmood, A.; Aslam, I., Synthesis of Novel $\mathrm{ZnV}_{2} \mathrm{O}_{4}$ Hierarchical Nanospheres and Their Applications as Electrochemical Supercapacitor and Hydrogen Storage Material. ACS Appl. Mater. Interfaces 2014, 6, 13635-13641.

(11) Yoo, H. D.; Liang, Y.; Li, Y.; Yao, Y., High Areal Capacity Hybrid Magnesium-lithiumion Battery with 99.9\% Coulombic Efficiency for Large-scale Energy Storage. ACS Appl. Mater. Interfaces 2015, 7, 7001-7007.

(12) Cao, Y.; Xiao, L.; Sushko, M. L.; Wang, W.; Schwenzer, B.; Xiao, J.; Nie, Z.; Saraf, L. V.; Yang, Z.; Liu, J., Sodium Ion Insertion in Hollow Carbon Nanowires for Battery Applications. Nano Lett. 2012, 12, 3783-3787.

(13) Hu, Z.; Wang, L.; Zhang, K.; Wang, J.; Cheng, F.; Tao, Z.; Chen, J., MoS 2 Nanoflowers with Expanded Interlayers as High-performance Anodes for Sodium-ion Batteries. Angew. Chem., Int. Ed. 2014, 53, 12794-12798.

(14) Kim, H.; Hong, J.; Park, Y.-U.; Kim, J.; Hwang, I.; Kang, K., Sodium Storage Behavior in Natural Graphite using Ether-based Electrolyte Systems. Adv. Funct. Mater. 2015, 25, 534-541. (15) Lotfabad, E. M.; Ding, J.; Cui, K.; Kohandehghan, A.; Kalisvaart, W. P.; Hazelton, M.; Mitlin, D., High-density Sodium and Lithium Ion Battery Anodes from Banana Peels. ACS Nano 2014, $8,7115-7129$.

(16) Ding, J.; Wang, H.; Li, Z.; Kohandehghan, A.; Cui, K.; Xu, Z.; Zahiri, B.; Tan, X.; Lotfabad, E. M.; Olsen, B. C.; Mitlin, D., Carbon Nanosheet Frameworks Derived from Peat Moss as High Performance Sodium Ion Battery Anodes. ACS Nano 2013, 7, 11004-11015. 
(17) Bai, Y.; Wang, Z.; Wu, C.; Xu, R.; Wu, F.; Liu, Y.; Li, H.; Li, Y.; Lu, J.; Amine, K., Hard Carbon Originated from Polyvinyl Chloride Nanofibers as High-performance Anode Material for Na-ion Battery. ACS Appl. Mater. Interfaces 2015, 7, 5598-5604.

(18) Wen, Y.; He, K.; Zhu, Y.; Han, F.; Xu, Y.; Matsuda, I.; Ishii, Y.; Cumings, J.; Wang, C., Expanded Graphite as Superior Anode for Sodium-ion Batteries. Nat. Commun. 2014, 5, 4033.

(19) Wu, Z.-S.; Ren, W.; Xu, L.; Li, F.; Cheng, H.-M., Doped Graphene Sheets as Anode Materials with Superhigh Rate and Large Capacity for Lithium Ion Batteries. ACS Nano 2011, 5, 5463-5471.

(20) Reddy, A. L. M.; Srivastava, A.; Gowda, S. R.; Gullapalli, H.; Dubey, M.; Ajayan, P. M., Synthesis of Nitrogen-doped Graphene Films for Lithium Battery Application. ACS Nano 2010, 4, 6337-6342.

(21) Paraknowitsch, J. P.; Thomas, A., Doping Carbons Beyond Nitrogen: An Overview of Advanced Heteroatom Doped Carbons with Boron, Sulphur and Phosphorus for Energy Applications. Energy Environ. Sci. 2013, 6, 2839-2855.

(22) Xu, J.; Wang, M.; Wickramaratne, N. P.; Jaroniec, M.; Dou, S.; Dai, L., High-performance Sodium Ion Batteries Based on a 3D Anode from Nitrogen-doped Graphene Foams. Adv. Mater. 2015, 27, 2042-2048.

(23) Ren, X.; Zhu, J.; Du, F.; Liu, J.; Zhang, W., B-doped Graphene as Catalyst to Improve Charge Rate of Lithium Air Battery. J. Phys. Chem. C 2014, 118, 22412-22418.

(24) Ling, C.; Mizuno, F., Boron-doped Graphene as a Promising Anode for Na-ion Batteries. Phys. Chem. Chem. Phys. 2014, 16, 10419-10424. 
(25) Sun, Y.; Du, C.; An, M.; Du, L.; Tan, Q.; Liu, C.; Gao, Y.; Yin, G., Boron-doped Graphene as Promising Support for Platinum Catalyst with Superior Activity Towards the Methanol Electrooxidation Reaction. J. Power Sources 2015, 300, 245-253.

(26) Han, J.; Zhang, L. L.; Lee, S.; Oh, J.; Lee, K.-S.; Potts, J. R.; Ji, J.; Zhao, X.; Ruoff, R. S.; Park, S., Generation of B-doped Graphene Nanoplatelets Using a Solution Process and Their Supercapacitor Applications. ACS Nano 2013, 7, 19-26.

(27) Cattelan, M.; Agnoli, S.; Favaro, M.; Garoli, D.; Romanato, F.; Meneghetti, M.; Barinov, A.; Dudin, P.; Granozzi, G., Microscopic View on a Chemical Vapor Deposition Route to Boron-doped Graphene Nanostructures. Chem. Mater. 2013, 25, 1490-1495.

(28) Wang, Y.; Li, L.; An, C.; Chen, C.; Jiao, L.; Yuan, H., Facile Synthesis of TiN Decorated Graphene and Its Enhanced Catalytic Effects on Dehydrogenation Performance of Magnesium Hydride. Nanoscale 2014, 6, 6684-6691.

(29) Spitler, E. L.; Dichtel, W. R., Lewis Acid-catalysed Formation of Two-dimensional Phthalocyanine Covalent Organic Frameworks. Nat. Chem. 2010, 2, 672-677.

(30) Hou, J.; Cao, C.; Idrees, F.; Ma, X., Hierarchical Porous Nitrogen-doped Carbon Nanosheets Derived from Silk for Ultrahigh-capacity Battery Anodes and Supercapacitors. $A C S$ Nano 2015, 9, 2556-2564.

(31) Yang, J.; Xie, J.; Zhou, X.; Zou, Y.; Tang, J.; Wang, S.; Chen, F.; Wang, L., Functionalized N-doped Porous Carbon Nanofiber Webs for a Lithium-sulfur Battery with High Capacity and Rate Performance. J. Phys. Chem. C 2014, 118, 1800-1807.

(32) Wang, H. G.; Wu, Z.; Meng, F. L.; Ma, D. L.; Huang, X. L.; Wang, L. M.; Zhang, X. B., Nitrogen-doped Porous Carbon Nanosheets as Low-cost, High-performance Anode Material for Sodium-ion Batteries. ChemSusChem 2013, 6, 56-60. 
(33) Zhou, X.; Zhu, X.; Liu, X.; Xu, Y.; Liu, Y.; Dai, Z.; Bao, J., Ultralong Cycle Life Sodiumion Battery Anodes Using a Graphene-templated Carbon Hybrid. J. Phys. Chem. C 2014, 118, 22426-22431.

(34) Bordes, A.; Eom, K.; Fuller, T. F., The Effect of Fluoroethylene Carbonate Additive Content on the Formation of the Solid-electrolyte Interphase and Capacity Fade of Li-ion Fullcell Employing Nano Si-graphene Composite Anodes. J. Power Sources 2014, 257, 163-169.

(35) Liao, L.; Cheng, X.; Ma, Y.; Zuo, P.; Fang, W.; Yin, G.; Gao, Y., Fluoroethylene Carbonate as Electrolyte Additive to Improve Low Temperature Performance of $\mathrm{LiFePO}_{4}$ Electrode. Electrochim. Acta 2013, 87, 466-472.

(36) Seng, K. H.; Li, L.; Chen, D.-P.; Chen, Z. X.; Wang, X.-L.; Liu, H. K.; Guo, Z. P., The Effects of FEC (Fluoroethylene Carbonate) Electrolyte Additive on the Lithium Storage Properties of NiO (Nickel Oxide) Nanocuboids. Energy 2013, 58, 707-713.

(37) Choi, N.-S.; Lee, Y.; Kim, S.-S.; Shin, S.-C.; Kang, Y.-M., Improving the Electrochemical Properties of Graphite/LiCoO 2 Cells in Ionic Liquid-containing Electrolytes. J. Power Sources 2010, 195, 2368-2371.

(38) Tang, K.; Fu, L.; White, R. J.; Yu, L.; Titirici, M.-M.; Antonietti, M.; Maier, J., Hollow Carbon Nanospheres with Superior Rate Capability for Sodium-based Batteries. Adv. Energy Mater. 2012, 2, 873-877.

(39) Wang, Y.-X.; Chou, S.-L.; Liu, H.-K.; Dou, S.-X., Reduced Graphene Oxide with Superior Cycling Stability and Rate Capability for Sodium Storage. Carbon 2013, 57, 202-208.

(40) Wang, Z.; Qie, L.; Yuan, L.; Zhang, W.; Hu, X.; Huang, Y., Functionalized N-doped Interconnected Carbon Nanofibers as an Anode Material for Sodium-ion Storage with Excellent Performance. Carbon 2013, 55, 328-334. 
(41) Luo, W.; Bommier, C.; Jian, Z.; Li, X.; Carter, R.; Vail, S.; Lu, Y.; Lee, J.-J.; Ji, X., Lowsurface-area Hard Carbon Anode for Na-ion Batteries via Graphene Oxide as a Dehydration Agent. ACS Appl. Mater. Interfaces 2015, 7, 2626-2631.

(42) Prabakar, S. J. R.; Jeong, J.; Pyo, M., Nanoporous Hard Carbon Anodes for Improved Electrochemical Performance in Sodium Ion Batteries. Electrochim. Acta 2015, 161, 23-31.

(43) Dirican, M.; Lu, Y.; Ge, Y.; Yildiz, O.; Zhang, X., Carbon-confined $\mathrm{SnO}_{2}$ Electrodeposited Porous Carbon Nanofiber Composite as High-capacity Sodium-ion Battery Anode Material. ACS Appl. Mater. Interfaces 2015, 7, 18387-18396.

(44) Wang, P.; Qiao, B.; Du, Y.; Li, Y.; Zhou, X.; Dai, Z.; Bao, J., Fluorine-doped Carbon Particles Derived from Lotus Petioles as High-performance Anode Materials for Sodium-ion Batteries. J. Phys. Chem. C 2015, 119, 21336-21344.

(45) Wang, H.; Hu, P.; Yang, J.; Gong, G.; Guo, L.; Chen, X., Renewable-juglone-based Highperformance Sodium-ion Batteries. Adv. Mater. 2015, 27, 2348-2354.

(46) Luo, X.-F.; Yang, C.-H.; Peng, Y.-Y.; Pu, N.-W.; Ger, M.-D.; Hsieh, C.-T.; Chang, J.-K., Graphene Nanosheets, Carbon Nanotubes, Graphite, and Activated Carbon as Anode Materials for Sodium-ion Batteries. J. Mater. Chem. A 2015, 3, 10320-10326.

(47) Li, H.; Shen, F.; Luo, W.; Dai, J.; Han, X.; Chen, Y.; Yao, Y.; Fu, K.; Zhu, H.; Hitz, E. M.; Hu, L., Carbonized Leaf Membrane with Anisotropic Surfaces for Sodium Ion Battery. ACS Appl. Mater. Interfaces 2016, 8, 2204-2210.

(48). Zheng, P.; Liu, T.; Yuan, X.; Zhang, L.; Liu, Y.; Huang, J.; Guo, S., Enhanced Performance by Enlarged Nano-pores of Holly Leaf-derived Lamellar Carbon for Sodium-ion Battery Anode. Sci. Rep. 2016, 6, 26246. 
(49). Wen, Y.; Wang, B.; Luo, B.; Wang, L., Long-Term Cycling Performance of NitrogenDoped Hollow Carbon Nanospheres as Anode Materials for Sodium-Ion Batteries. Eur. J. Inorg. Chem. 2016, (13-14), 2051-2055.

(50). Wang, M.; Yang, Z.; Li, W.; Gu, L.; Yu, Y., Superior Sodium Storage in 3D Interconnected Nitrogen and Oxygen Dual-Doped Carbon Network. Small 2016, 12, 2559-66.

(51). Wenzel, S.; Hara, T.; Janek, J.; Adelhelm, P., Room-temperature Sodium-ion batteries: Improving the Rate Capability of Carbon Anode Materials by Templating Strategies. Energy Environ. Sci. 2011, 4, 3342-3345.

(52). Song, H.; Li, N.; Cui, H.; Wang, C., Enhanced storage capability and kinetic processes by pores- and hetero-atoms- riched carbon nanobubbles for lithium-ion and sodium-ion batteries anodes. Nano Energy 2014, 4, 81-87.

(53). Fu, L.; Tang, K.; Song, K.; van Aken, P. A.; Yu, Y.; Maier, J., Nitrogen doped porous carbon fibres as anode materials for sodium ion batteries with excellent rate performance. Nanoscale 2014, 6, 1384-1389.

(54). Li, W.; Zeng, L.; Yang, Z.; Gu, L.; Wang, J.; Liu, X.; Cheng, J.; Yu, Y., Free-standing and binder-free sodium-ion electrodes with ultralong cycle life and high rate performance based on porous carbon nanofibers. Nanoscale 2014, 6, 693-698. 


\section{TABLE OF CONTENTS}

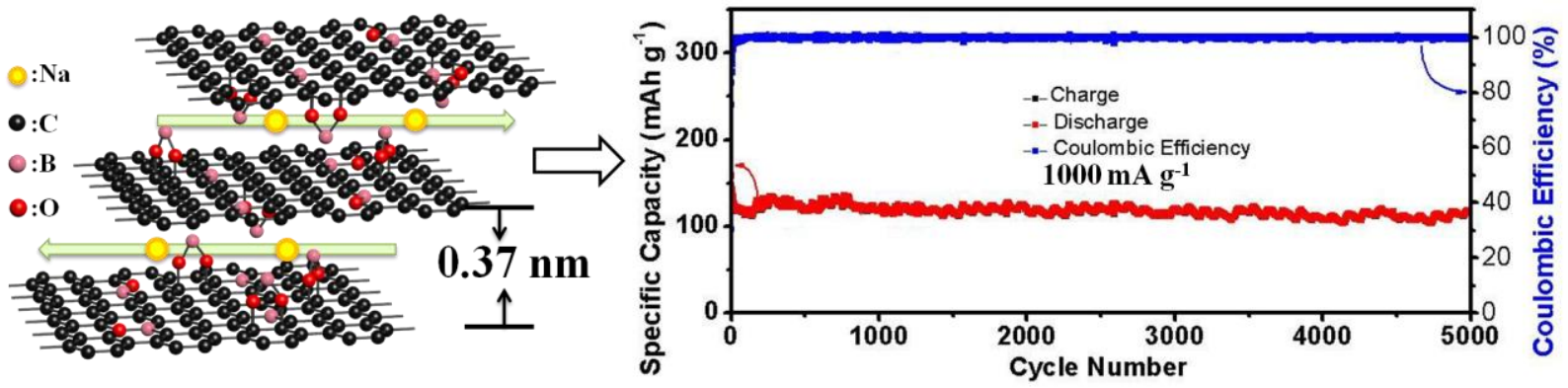

